\title{
Exploring adolescents' perception of accessibility and its influence on park use
}

\author{
Zohreh Mahdiar* and Melasutra bt Md Dali \\ Department of Urban and Regional Planning, Faculty of Built Environment, University of Malaya, 50603 \\ Kuala Lumpur, Malaysia \\ *zohreh.mahdiar@gmail.com
}

\begin{abstract}
The fundamentals of urban planning suggest that accessibility to public open spaces, particularly the parks, is supposed to contribute to the increased use of them. Accessibility is a difficult and complex concept to define and measure. Moreover, literature review shows few researches have defined the concept of accessibility from the perspectives of potential park users and its influence on individuals' behavior. This study aims to define factors adolescents find important in perceiving whether a park is accessible and the influence of accessibility on the use of urban parks for adolescents aged 15-18. This qualitative study's findings are based on interviews with a group of 17 male and female adolescents. The findings show that the perception of the accessibility concept among adolescents is an outcome of different parameters such as proximity, travel time, presence/non-presence of traffic, availability of transportation, etc. The results of this study contribute to enhancing the understanding of the accessibility concept as a multi-dimensional construct from adolescents' point of view, and its influence on the use of parks.
\end{abstract}

Keywords: Accessibility, Park use, Adolescents, Qualitative Study

\section{INTRODUCTION}

Parks provide opportunities for physical activity, enjoyment of nature, social interaction, and escape, and they contribute to the improved health and wellbeing of users (Payne, Orsega-Smith, Roy, \& Godbey, 2005; Potwarka, Kaczynski, \& Flack, 2008). For adolescents, who are the target population of this study, parks provide spaces to explore and develop their social and individual identities (Lloyd, Burden, \& Kiewa, 2008). Parks are also suggested as an antidote to the passive lifestyle of adolescents and the commercialization of leisure facilities (Burgess, Harrison, \& Limb, 1988). Therefore, increasing park use can improve adolescents' health and contribute to solving problems related to adolescents' passive lifestyle such as obesity, hostility and aggressiveness, increasing impatience and depression, isolationism and escaping from society, and increasing shyness and lack of self-confidence in adolescents (Rey-López, Vicente-Rodríguez, Biosca, \& Moreno, 2008).

According to the socio-ecological model, the behavior 'use of urban parks' can be influenced by environmental factors (e.g., physical environment, social environment, cultural environment, and policy environment) (Giles Corti, 2006; Raymore, 2002). Therefore, an increasing number of new researches have focused on understanding which park characteristics relate to park use (Bedimo-Rung, Mowen, \& Cohen, 2005; Cohen et al., 2009; Cohen et al., 2010; Loukaitou-Sideris \& Sideris, 2010; McCormack, Rock, Toohey, \& Hignell, 2010). Access is indicated as one of the influential park characteristics of park use in the conceptual model presented by Bedimo-Rung et al. (2005) (See Figure 1). Previous studies also have investigated the influence of accessibility on park use (Andrew $\mathrm{T}$ Kaczynski et al., 2014; Andrew J Mowen \& Confer, 2003a; Walker \& Crompton, 2012). However, information in the literature on the influence of accessibility on adolescents' use of parks is sparse. Only a few studies that have investigated park use among adolescents have pointed out accessibility as an influential factor relating to park use (Babey, Wolstein, Krumholz, Robertson, \& Diamant, 2013; Lloyd et al., 2008; Loukaitou-Sideris \& Sideris, 2010; Ries et al., 2009; J. Veitch, Salmon, \& Ball, 2007).

Moreover, while accessibility has now evolved into a multidimensional construct, current open-space planning models still use physical proximity to parks as a proxy variable to evaluate 'accessibility' (Babey et al., 2013; Andrew T Kaczynski et al., 2014; A. Mowen, Orsega-Smith, Payne, Ainsworth, \& Godbey, 2007; Neuvonen, Slevanen, Tonnes, \& Koskela, 2007). This approach tends to overlook the complexity 


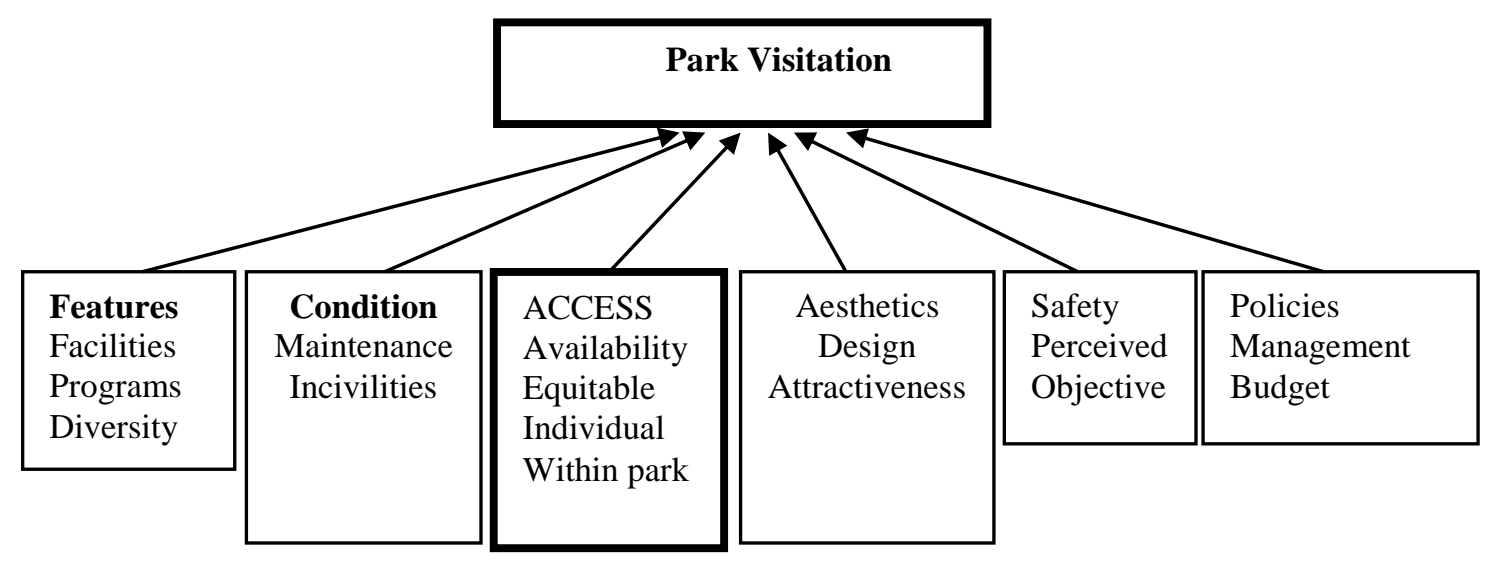

Figure 1: Park characteristics that influence park use (Bedimo-Rung et al., 2005)

of the 'accessibility' concept (Wang, Brown, \& Liu, 2015; Wang, Mateo-Babiano, \& Brown, 2013). Therefore, studies on accessibility and park use have used quantitative approaches in which urban planning experts developed the measures of park accessibility. For example, in urban park planning, park planners use physical indices such as distance and proximity, total park area, park area per capita, and number of parks, as criteria to evaluate the level of access of public parks (Babey et al., 2013; Andrew T Kaczynski et al., 2014; Oh \& Jeong, 2007). These indices, however, are orientated towards the spatial-physical dimension of park accessibility. Although the physical standard provides a relatively easier and more straightforward means of operationalizing accessibility, it does not represent people's perceptions of accessibility. The latter is claimed to be critical in gaining a better understanding of human behavior and predicting it, subject to personal values and constraints. These arguments highlight the importance of exploring the concept of accessibility to develop a more thorough understanding of the concept in the planning context and to argue for a more comprehensive definition of accessibility that includes different dimensions of the concept (Wang, Brown, \& Mateo-Babiano, 2013). Therefore, it is necessary to examine accessibility from the perspective of potential park users. In this respect, qualitative research has been conducted to understand adolescents' perceptions of accessibility and their influence on park use.

This study tries to answer these research questions: 1) What is the perception of adolescents towards "accessibility" and "accessible parks"? 2) How do adolescents' perceptions of accessibility influence their park use?

This study's results identify measures for assessing accessibility to parks for the purpose of using them from adolescents' perspectives. This investigation did not separate the dimensions defining accessibility, as accessibility is not an abstract concept and people routinely evaluate and integrate multiple dimensions, resulting in behavioral choices for the use (or non-use) of urban facilities such as parks (Wang, Brown, et al., 2013).

\section{METHODOLOGY}

Shiraz and adolescents aged 15-18 were respectively considered as study area and target population of this study. Shiraz is known as the "city of gardens", due to the numerous gardens and fruit trees existing in the city and people especially adolescents of Shiraz were famous using parks and nature in the past. However, recently conducted research showed their use has significantly decreased compared to the past and the adolescents who were perceived as the main users of parks are now inclined to use other new modernized public spaces such as shopping centers (Iran Ministry of Islamic Culture. National Plans Office, 2010). This specific age group was chosen because the issue of adolescents and parks accessibility has not yet been addressed in any of the previous studies of adolescents and parks in Iran. Moreover, the adolescents aged between 15-18, who are high school students in Iran, were selected because this age group of high school students (or middle and late adolescents), are typically more mobile than younger adolescents and therefore can choose the places they visit (Davis \& Jones, 1996).

\subsection{STUDY AREA}

Shiraz, capital of Fars Province, is located in the southwest of Iran and is the sixth-biggest city in the country (See Figure 2). Situated $1500 \mathrm{~m}$ above sea level (grid coordinates $29 \circ 53$ N, 52०58'E), Shiraz covers an area of about $340 \mathrm{~km}^{2}$. The city is located in a NW-SE elongated valley bounded by the Zagros 
Mountains and was built over a green plain of the Zagros Mountains. Shiraz has a moderate climate with four regular seasons. The daily temperature varies between $40 \circ \mathrm{C}$ in summer and $-10 \circ \mathrm{C}$ in winter.

According to the 2006 census, Shiraz has a population of 1.3 million. Of this number, $19.6 \%$ are adolescents aged 10-19 and $11.5 \%$ are adolescents aged 15-18. Among the adolescent population, $51.5 \%$ are male and $48.5 \%$ are female (Shiraz Municipality, 2010). Shiraz is known as the "City of Gardens," due to the numerous gardens and fruit trees in the city. Green space per capita for the residents of Shiraz should be $14.55 \mathrm{~m} 2$, but is currently $5 \mathrm{~m} 2$. Shiraz has 108 neighborhood parks, 27 local parks, 35 district parks, and 15 city parks. Park land space per capita in Shiraz is $1.58 \mathrm{~m} 2$. (Shiraz Municipality, 2010).

\subsection{METHOD}

Semi-structured interviews with 17 teenagers were conducted at the four selected high schools over a period of three weeks in October 2012. These teenagers were chosen from males and females between the ages of 15 and 18. The participants were chosen from four randomly selected high schools in four different socioeconomic status areas of "Shiraz." A requirement for participation was that the respondents should have visited urban parks in Shiraz once or more times in the six months preceding the interviews. Participants freely chose to participate and share their experiences.

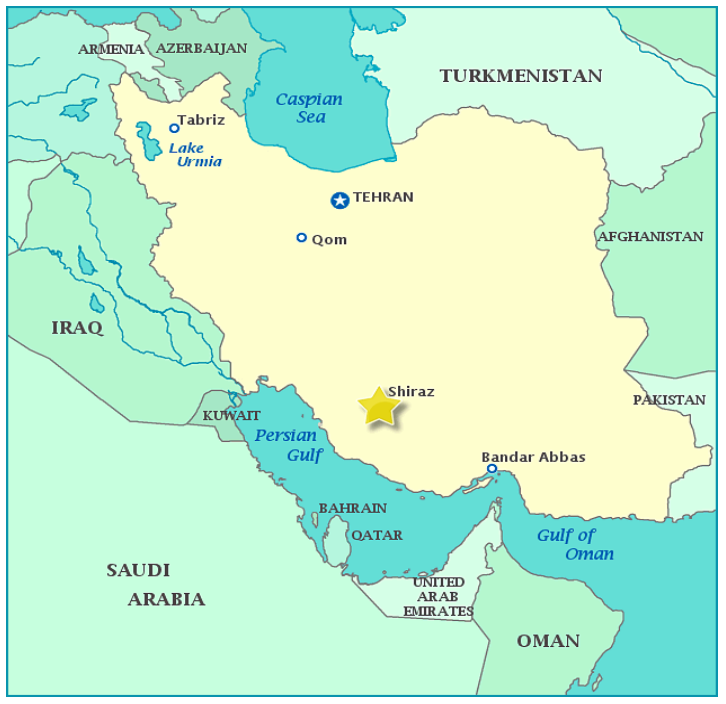

Figure 2: Shiraz location in Iran map

The study's researchers decided to conduct interviews until the saturation level was reached, i.e., when more interviews did not add to the knowledge that resulted from the interviews or provide more insights. This resulted in 17 participants (Saunders, Saunders, Lewis, \& Thornhill, 2009). The study participants were chosen based on convenient sampling from four high schools (two for males and two for females). To obtain a variety of perspectives, criterion sampling was used to select participants by age and gender. There was an almost equal number of young men (8) and young women (9). The participants were fairly evenly distributed across the four grades. Two male and two female adolescents were selected from each grade.

The interviews were conducted in a private room located in each study high school. The length of the interviews varied from 20 to 35 minutes. Interviews were tape recorded with the permission of the respondents and transcribed verbatim. All participants were identified using codes to ensure anonymity. The students were asked to identify the factors that influenced them to perceive parks as being more accessible. Moreover, they were asked to explain how these parameters related to accessibility influenced their use of parks.

The researchers used qualitative analytic techniques, including coding and thematic development (Babbie, 2007; Neuman, 2004). The coding process was conducted by hand; the emphasis was on revealing the multiple perspectives of participants and interpreting their narratives in the context of their social worlds. Although it was considered important to include a presentation of adolescents from various age groups and SES areas, this study did not aim specifically to investigate the influence of age or SES differences, and therefore the results have not been presented separately for each age or SES group.

Participant validation was conducted and the results were presented to four respondents for feedback on the accuracy of the findings and validation of the interpretation and explanations that were developed (Hennink, Hutter, \& Bailey, 2010).

\section{FINDINGS AND DISCUSSION}

Based on the thematic analysis, the researcher found ten (10) themes that summarize the parameters impacting adolescents' perception of accessibility. These include proximity, travel time, presence/none presence of traffic, availability of transportation, ease of access, safe access, attractive access, parking availability, number of park entrances and location of parks. These themes are described in details based on adolescents' descriptions. 


\subsection{ADOLESCENTS PERCEPTION OF ACCESSIBILITY AND PARK USE}

The results of this study show that adolescents perceive the parameters of proximity, travel time, presence/non-presence of traffic on routes linking adolescents' houses to parks, transportation, ease of access, safe access, attractive access, parking availability, number of entrances, and location as influential in making parks more accessible. Distance from home to park, travel time from home to park, and ease of access were the most important factors influencing adolescents' perceptions that a park was accessible The following discussion will elaborate on how these parameters influence adolescents' use of parks.

\subsubsection{Proximity}

Proximity was the first indicator of accessibility for adolescents in this study. Adolescents valued proximate parks for different reasons. Firstly, some female adolescents preferred to use urban parks, which are located in an area with the same SES characteristics of the place where they live. Furthermore, a proximate park means it is frequented by people from the same SES. For example, Female 1 (18 years) stated:

"It's better if the park is closer. Culture [of the people] is different in various parts of the city. People who live in the same area generally are culturally similar to each other; therefore, I prefer going to parks in areas near my house."

Secondly, the adolescents did not have to waste time traveling to and from parks over long distances, risk being stuck in traffic jams, or wait to find appropriate safe transportation. Accordingly, they had more time to spend with friends while they were using parks close to their homes. The adolescents expressed the view that the remoteness of a park from their house could be a deterrent to using the park, because going to the park by road would take a lot of time. Choosing a park closer to home or even near other places such as shopping centers meant the adolescents could spend more time with their friends.

"Sometimes we decide to go to park, but when we calculate the time we have to spend on a heavy traffic to reach the park, we prefer to go to a shopping center near our home for a walk rather than a park." (Female 5,16 years)

"Proximity of a park is important. Koohpayeh Park is a good park, but we can't go there because it is far away, we don't have enough time and also it's not easily accessible and we feel inconvenient." (Male 3, 17 years)

This can be explained by the fact that adolescents' use of space is strongly linked to their developmental needs of social relatedness (Lloyd et al., 2008; Travlou \& Ward Thompson, 2007), which is why being together is very important for them.

Residents' proximity to parks has been examined as an indicator of park access in previous studies as well (Booth, Owen, Bauman, Clavisi, \& Leslie, 2000; Giles-Corti \& Donovan, 2002). Residents' greater proximity to a park was related to increased park use (Albert, Abo-Kalla, \& Baron, 2011; Bedimo-Rung et al., 2005; Dunnett, Swanwick, \& Wolley, 2002; Evenson, Sarmiento, Macon, Tawney, \& Ammerman, 2002; Giles-Corti et al., 2005; Giles-Corti \& Donovan, 2002; Holman, Donovan, \& Corti, 1996; A. Mowen et al., 2007; Andrew J Mowen \& Confer, 2003b; A. J. Mowen, Payne, \& Scott, 2005; Neuvonen et al., 2007; Pasaogullari \& Doratli, 2004; Jasper Schipperijn et al., 2010; Schipperijn, Stigsdotter, Randrup, \& Troelsen, 2010; Scott \& Jackson, 1996; Troped et al., 2001; Tucker, Gilliland, \& Irwin, 2007; Van Herzele \& Wiedemann, 2003; Jenny Veitch, Bagley, Ball, \& Salmon, 2006). Three studies on early adolescents' use of parks also showed the importance of proximity to home parks on park use (Jansson \& Persson, 2010; Loukaitou-Sideris \& Sideris, 2010; J. Veitch et al., 2007). For example, Loukaitou-Sideris and Sideris (2010) argued that lower level of car ownership among households as one of the reasons cause early adolescents walk to the park and proximity become important. However, the importance of proximity on park use is influenced by respondents' age, behavior and mobility. For example, because of the potential limited mobility of certain age groups such as children and the elderly, proximity is much more important to them (Grahn, 1991) than it is to middle to late adolescents (15-18 years), who have independent mobility and developmental needs to move beyond the neighborhood (Lloyd et al., 2008; Schiavo, 1988). One of these needs is autonomy and the desire for separation from family (Larson \& Lowe, 1990).

\subsubsection{Travel Time}

Levinson (1998) suggests travel time as an important measure of accessibility. He believes accessibility is defined by the product of two measures, a temporal element that refers to travel time between two points, and a spatial element. The results of this study also showed adolescents consider travel time as a measure of accessible parks, and this was found to influence their use of parks. The results are consistent with previous researches in two adult population studies 
(Scott \& Jackson, 1996; Tinsley, Tinsley, \& Croskeys, 2002) and one study that focused on adolescents' park use (Ries et al., 2009).

Travel time influences adolescents' use of parks for different reasons. During the school term, especially on weekdays, their free time is limited. As mentioned before, distant parks take a lot of travel time and pose the potential risk of commuters being stuck in a traffic jam or waiting to find appropriate and safe transportation. Therefore, adolescents prefer to spend their limited free time being together somewhere close to their homes, instead of wasting it trying to access a park.

Adolescents' dependence on their parents for using urban parks was a second reason that influenced their concern about travel time. This applied particularly to female and younger adolescents who are dependent on their families to use parks. Their parents were not keen to waste their limited time on road trips to access parks with the desired facilities. Female 5 (16 years) stated:

"Traffic is a very important factor. Because I go to parks with my parents and since both of them work, they have little spare time to waste in traffic jams. We lose a lot of time on the road to reach the parks because they are located in crowded areas. We become bored and tired after long journeys in traffic."

However, the importance of distance and travel time are affected by the visit days and are less important on holidays because adolescents and their families have more free time on weekends. Moreover, there are less traffic jams on holidays. According to Female 4 (17 years), during holidays when adolescents have more free time, they prefer going to bigger parks that have more facilities, but on workdays when there is not enough time, they prefer to spend their leisure time at neighborhood parks:

"In weekdays we prefer choosing parks near our home rather than parks with more facilities, but in holidays that we have enough time we opt for parks with more facilities, although they are far away."

\subsubsection{Presence/Non-Presence of Traffic}

Presence or non-presence of traffic on linking routes to the parks was another indicator that influenced adolescents to perceive a park as accessible. High traffic volume was an issue respondents mentioned frequently because it was one of the reasons that increased travel time and influenced accessibility to a park. Moreover, being stuck in traffic makes adolescents tired and bored. Therefore, some adolescents prefer parks in traffic-free areas, even if they are not equipped with the desired play equipment. Previous studies have also reported heavy traffic as one of the features of urban environments that obstruct the use of parks among drivers and pedestrians as it impedes their access to parks (Bedimo-Rung et al., 2005; Chawla, 2001; Lynch, 1977; Troped et al., 2001; Van Herzele \& Wiedemann, 2003). Shores and West (2010) mentioned that the geographic concentration of urban residents increases traffic jams and makes park access problematic. They argued that reasonable travel distances are influenced by traffic and therefore may differ within urban and rural areas. One reason is that driving five miles in the countryside may be much quicker than traveling through five miles of urban traffic.

\subsubsection{Availability Of Transportation}

To some adolescents, parks that can be reached with convenient, safe, and cheap transportation are accessible. Finding appropriate, safe transportation to travel to and from parks, as well as considerations relating to transportation costs and operating hours were issues some respondents mentioned as forcing them to use parks closer to home. The availability of convenient, safe, and cheap transportation with extended operating hours to travel to and from the park was considered influential on adolescents' park use.

"There is a long way from our home to Azadi Park. If I go by taxi it would cost me a lot and if I go by bus, which is less expensive, all my time would be wasted ... When the park is far from home, because of the time we lose to get there we can't spend a lot of time in the park. Since when it becomes late at night, public transportation does not operate and it is difficult to find a safe transportation to go back home." (Male 2, 18 years)

Previous studies have also pointed out the importance of transportation and its type in relation to park use (Gold, 1977; Grow et al., 2008; Lau \& Chiu, 2003; Pasaogullari \& Doratli, 2004). For example, availability of public transportation and car ownership is considered important in promoting accessibility to public open spaces such as parks (Lau \& Chiu, 2003). Other than transportation itself, characteristics of the transport environment also influence accessibility to parks (Pasaogullari \& Doratli, 2004). Some other studies have emphasized the influence of active transportation (walking/biking) on increased park use (Grow et al., 2008; Loukaitou-Sideris \& Sideris, 2010; Neuvonen et al., 2007). For example, walking/biking to parks is associated with frequent use of parks by 
children and adolescents (Grow et al., 2008; Loukaitou-Sideris \& Sideris, 2010). Walking/biking increases accessibility of parks when parents are unwilling or unavailable to provide transportation. Active transportation to parks is associated with safe, well-connected street networks to and from home to a park, increased perceived traffic safety, enhanced pedestrian/bicycling roads, the non-existence of the crime threat, the presence of overpasses, and traffic lights (Grow et al., 2008; Loukaitou-Sideris \& Sideris, 2010).

To some adolescents, the presence of convenient transportation to and from parks was more important than having a park close to home.

"Proximity of the park and being able to reach the park [by] walking is not too important to me, as long as being able to get to the park easily by taxi or any other vehicle is important." (Male 4, 17 years).

\subsubsection{Ease Of Access}

According to some respondents in this study, easy access to a park is more important than being close to it. Lack of well-connected routes, lack of wellconnected transportation that requires several trips to access the park, and crowded streets with heavy traffic make access inconvenient for a youngster.

"Sometimes the park is not too far, but it is not easily accessible and one has to get in and out of taxies several times in order to reach the park, which is very inconvenient." (Male 2, 18 years)

"Sometimes the park is far away from home, but it is easily accessible because we use underpasses and overpasses or the streets with light traffics to get to the park. Sometime a park is near but we are stuck in such a heavy traffic that it takes a long time to get to the park." (Female, 16 years)

Previous studies have also discussed some parameters that make the accessibility of parks more convenient. For example, for those who drive to access parks, local streets are preferable and more convenient than major roads (Pasaogullari \& Doratli, 2004), and the existence of major roads decreases accessibility (Giles-Corti et al., 2005). For those who need to walk through surrounding areas in order to access parks, the slope of the terrain (Bedimo-Rung et al., 2005) and continuity of sidewalks (Calthorpe, 1993) have an impact on accessibility and park use.

\subsubsection{Safe Access}

Safety of routes was mentioned as an important factor that increases accessibility to parks and park use (Gold, 1977; Loukaitou-Sideris \& Sideris, 2010). Safety could be categorized in two dimensions: Safety from crime and safety from injury (Humpel, Owen, \& Leslie, 2002). However, respondents in this study mentioned safety from crime as one of their concerns while they want to access specific parks. Their concerns reflected that proximity and ease of access to parks are not sufficient and that the routes to parks must be safe as well.

"We will never go to Laleh Park, because the access route is not safe and we face a lot of problems along the way to the park... The surrounding area of the park also is not safe... It is very important that a park is situated in a good and safe area of the city." (Male 3, 17 years)

"Although the way to Jannat Park is short, it is not safe and we can't go to the park walking." (Female 1,18 years)

Previous studies that have focused on children (Loukaitou-Sideris \& Sideris, 2010) and older adults (Parra, Gomez, Fleischer, \& David Pinzon, 2010) have considered traffic safety (safety of injury) as a factor that could increase accessibility and use of parks. For example, a study on older adults found that older adults residing in areas with a high-connectivity index (a high number of street intersections) were less likely to use parks. It is possible that areas with a high connectivity index are proportionately related to a larger number of intersections with higher rates of traffic accidents involving pedestrians. This could potentially create a sense of fear among people, especially older adults or their families, and ultimately prevent them from using parks (Parra et al., 2010).

\subsubsection{Attractive Access}

Our findings showed that the attractiveness of routes leading to parks influences adolescents' perceptions of accessibility. Female 1 (18 years) mentioned how the lack of attractive routes to parks, prevents her and her family from accessing parks on foot.

"Although the way to Jannat Park is short, it is not safe and we can't go to the park walking; moreover, the access route has no attractions... there are a lot of auto repair shops on the way to the park... despite the proximity of the park, we prefer to go by our own vehicle [instead of walking]." (Female 1, 18 years)

Previous studies have emphasized that improving the attractiveness of access routes to encourage park 
use should be considered. For example, sidewalks should be designed by architects and the design should incorporate diversity, human scale, and beautiful details (Calthorpe, 1993). Mixed land use also offers people attractions and increases the sense of community and level of safety among those who navigate surrounding areas in order to access parks. This could potentially increase park use (BedimoRung et al., 2005; Parra et al., 2010). Living in an area with more than two types of land use, such as residential and commercial, could motivate people to leave their houses and go for a walk, and potentially to a nearby park. This could be particularly relevant for the older adult population who may base their decision to visit a park or not on the availability of other attractions or establishments surrounding the parks, for example a small convenience store or a coffee shop. Mixed land use offers people attractions and increases the sense of community and level of safety (Parra et al., 2010).

\subsubsection{Parking Availability}

Parking availability is another factor affecting adolescents' perception of accessibility and the use of parks. This factor is very important, particularly to adolescents who go to parks with their families (females and young adolescents) in their own personal family vehicles because it influences their parents' decision making.

"Parking is an important issue. Since we go to parks with our parents, this issue does not affect our decision on which park to visit, but lack of adequate parking space influences our parents' decision. My father disagrees to going to parks that do not have adequate parking space." (Female 8, 15 years)

Lack of adequate and safe parking space also influences the time teenagers spend in parks with their families. As Female 1 (18 years) stated:

"Because of the lack of adequate and safe parking spaces, families are concerned about car theft, and therefore cannot stay in the park for a long time."

One study investigated the influence of transport and environmental variables on people's use of playgrounds, with a focus on different cultures (Jewish and Arab), and indicated that parking availability had an impact on the Jewish population in using playgrounds (Albert et al., 2011).

\subsubsection{Number of Park Entrances}

The number of park entrances influences the way in which teenagers perceive parks as accessible. The study participants mentioned that when they were coming from different parts of the city and from different directions, the presence of entrances on different sides of the park helped them to access the park more easily.

"Jannat Park is a big park and only two entrances are available. When we are coming from different parts of the city to Jannat Park, we are obliged to come to these two entrances to enter the park." (Male 3, 17 years)

"Number of entrances is important. When the parks are very large, such as Jannat Park, because of the lack of parking space, my father is obliged to park our car out of the park. If it had more entrances, we could enter the park from the area [where] we have parked and we were not obliged to carry all the stuff we have brought from the house." (Ali, 16 years)

One study also argued that urban green spaces with multiple entrances that can be accessed from all sides are walkable, frequently used, and ranked as having a "high degree of access," more so than those parks which can be accessed from two sides with a "medium degree of access," and those which can be accessed from one side only - a "low degree of access" (Van Herzele \& Wiedemann, 2003).

\subsubsection{Location of Parks}

Parks located near adolescents' school or on their regularly walked routes are accessible for them and could increase their use of the park.

"There is a park near my school; we are always going there before going back to home." (Male 6, 16 years)

Previous studies have also argued that parks located on regularly walked routes (i.e., to and from school) are more accessible and more frequented than parks located elsewhere (Ferré, Guitart, \& Ferret, 2006). One study reported that facilities on a frequently used route were considered more 


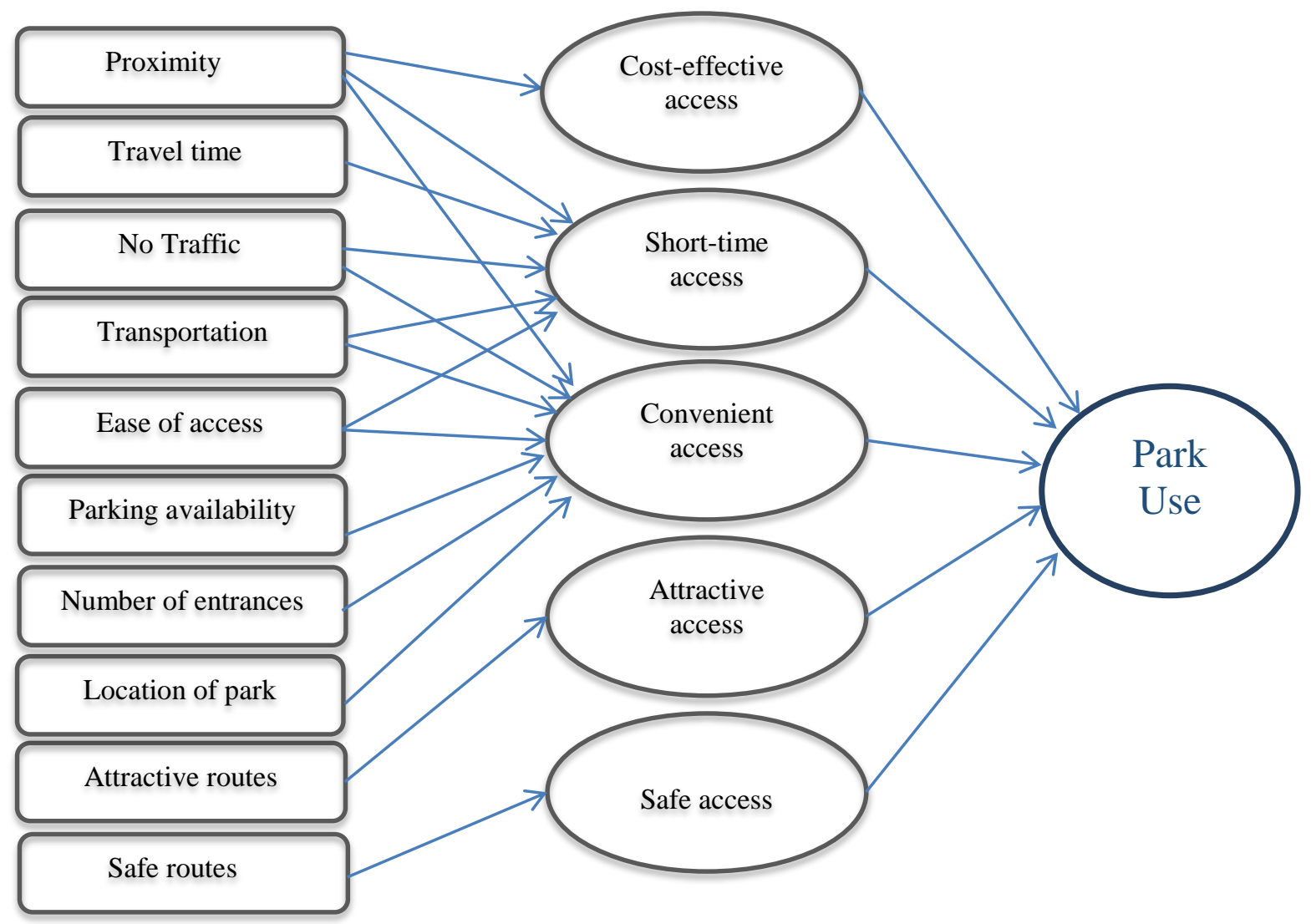

Figure 2: Adolescents' perception of accessibility

'convenient' than those closer to home (Sallis et al., 1990).

\subsection{ACCESSIBILITY ALONE DOES NOT DETERMINE ADOLESCENTS' USE OF PARKS}

Although the study's participants valued accessible parks, in the presence of other factors, the accessibility factor could be ignored. A number of adolescents believed other factors such as recreational facilities, safety, and social environment outweighed the influence of accessibility.

"The quality of a park is more important than the accessibility factor. If there is a good park near home, we will go there, otherwise we have to go to parks that are far away or perhaps not go at all." (Female 6, 16 years)

"Distance is important, but when a park has few facilities, one prefers to go to a park with more and better facilities even though it is far." (Female 2, 18 years)
"Our house is near to Valiasr Park, but it is so unsafe that I'm not willing to even cross it, let alone going to it." (Female 7, 16 years)

Previous studies also support the importance of other factors such as recreational facilities, safety, maintenance, and size of park over accessibility (Jansson \& Persson, 2010; Andrew T. Kaczynski, Potwarka, \& Saelens, 2008; Powell, Martin, \& Chowdhury, 2003; J. Schipperijn et al., 2010; Shores $\&$ West, 2010). Adolescents may ignore proximity and be willing to travel further to use certain parks with desired features. This may be related to the independent mobility of adolescents at this age (Gearin \& Kahle, 2006; Jansson \& Persson, 2010; J. Veitch, Salmon, \& Ball, 2008). For example, one study reported that the quality of parks and playgrounds is more important than accessibility, and quality turned out to have an effect on attendance when the level of mobility was rather high and older children in the study visited popular and unique playgrounds more often (Jansson \& Persson, 2010). In this respect, teenagers do not always visit the closest park and may be willing to travel further to use certain 
parks with desired features or facilities (Gearin \& Kahle, 2006; J. Veitch et al., 2008).

\section{CONCLUSION}

This study found that the perception of the accessibility concept among adolescents is an outcome of different parameters. These parameters include proximity, travel time, presence/non-presence of traffic, availability of transportation, ease of access, safe access, attractive access, parking availability, number of entrances of parks, and location of parks. The adolescents' explanation of how these parameters influence their access to parks, leads us to conclude that adolescents perceive five dimensions for accessibility. These are short-time access, costeffective access, convenient access, safe access, and attractive access. Improving each parameter can improve one or more dimension of accessibility among adolescents. For example, availability of safe parking lots in the park area could make parks more accessible by providing convenient access for adolescents and their families who access the parks with their own vehicle (see Figure 3).

\section{REFERENCES}

Albert, G.,Abo-Kalla, H., \& Baron, M. (2011). Transport and Environmental Variables and the Impact of Cultural Differences on Playground Use. Journal of Urban Planning and Development-Asce, 137(3), 291-297. doi:10.1061/(Asce)Up.1943-5444.0000064

Babbie, E. R. (2007). The Practice of Social Research (9th ed): Cengage Learning.

Babey, S. H., Wolstein, J., Krumholz, S., Robertson, B., \& Diamant, A. L. (2013). Physical Activity, Park Access and Park Use among California Adolescents.UCLA: UCLA Center for Health Policy

Bedimo-Rung, A. L., Mowen, A. J., \& Cohen, D. A. (2005). The significance of parks to physical activity and public health - A conceptual model. American Journal of Preventive Medicine, 28(2), 159-168. doi: 10.1016/j.ampre.2004.10.024

Booth, M. L., Owen, N., Bauman, A., Clavisi, O., \& Leslie, E. (2000). Social-cognitive and perceived environment influences associated with physical activity in older Australians. Journal of Preventive Medicine, 31(1), 1522. doi: 10.1006/pmed.2000.0661
Results of this research contribute to the body of extant knowledge by addressing the following gaps in the literature: First, it contributes to the limited research on the impact of accessibility on park use in adolescents aged 15-18. Secondly, it adds to the relatively limited number of qualitative studies that explore the perceptions of potential users (in this study; adolescents) towards accessibility and accessible parks.

The results of this research will hopefully persuade urban planners not only to consider distance as a proxy for accessibility, but also to consider more dimensions of this concept among different age groups. This study suggests urban planners should consider and examine these parameters to facilitate access to public parks, which will improve park use among adolescents.

Future studies should quantitatively examine the influence of these parameters on park use. This would contribute to the development of interventions by identifying which parameters are actually associated with park use among adolescents.

Burgess, J., Harrison, C. M., \& Limb, M. (1988). People, parks and the urban green: a study of popular meanings and values for open spaces in the city. Urban studies, 25(6), 455.

Calthorpe, P. (1993). The next American metropolis: Ecology, community, and the American dream. New York: Princeton Architectural Press.

Chawla, L. (2001). Putting young old ideas into action: the relevance of growing up in cities to local Agenda 21. Local Environment, 6(1), 13-25.

Cohen, D. A., Golinelli, D., Williamson, S., Sehgal, A., Marsh, T., \& McKenzie, T. L. (2009). Effects of park improvements on park use and physical activity policy and programming implications. American Journal of Preventive Medicine, 37(6), 475480. doi: 10.1016/j.amepre.2009.07. 017

Cohen, D. A., Marsh, T., Williamson, S., Derose, K. P., Martinez, H., Setodji, C., \& McKenzie, T. L. (2010). Parks and physical activity: Why are some parks used more than others? Journal of Preventive Medicine, 50, S9-S12. doi: 10.1016/j.ypmed.2009.08. 020

Davis, A., \& Jones, L. J. (1996). Children in the urban environment: an issue for the new 
public health agenda. Health \& Place, 2(2), 107-113.

Dunnett, N., Swanwick, C., \& Wolley, H. (2002). Improving Urban Park, Play Areas and Green Spaces: Department for Transport, Local Government and the Regions.

Evenson, K. R., Sarmiento, O. L., Macon, M. L., Tawney, K. W., \& Ammerman, A. S. (2002).

Environmental, policy, and cultural factors related to physical activity among Latina Immigrants. Women \& Health, 36(2), 43-56.

Ferré, M. B., Guitart, A. O., \& Ferret, M. P. (2006). Children and playgrounds in Mediterranean cities. Children's Geographies, 4(2), 173183.

Gearin, E., \& Kahle, C. (2006). Teen and adult perceptions of urban green space in Los Angeles. Children, Youth and Environments, 16(1), 25-48.

Giles-Corti, B., Broomhall, M. H., Knuiman, M., Collins, C., Douglas, K., Ng, K., Donovan, R. J. (2005). Increasing walking: how important is distance to, attractiveness, and size of public open space? American Journal of Preventive Medicine, 28(2), 169-176.

Giles-Corti, B., \& Donovan, R. J. (2002). The relative influence of individual, social and physical environment determinants of physical activity. Social Science \& Medicine, 54(12), 1793-1812. doi: 10.1016/s02779536(01)00150-2

Giles Corti, B. (2006). People or places: What should be the target? Journal of Science and Medicine in Sport, 9(5), 357-366. doi: 10.1016/j.jsams.2006.06.021

Gold, S. M. (1977). Neighborhood Parks The Nonuse Phenomenon. Evaluation Review, 1(2), 319-328.

Grahn, P. (1991). Landscapes in our minds: people's choice of recreative places in towns. Landscape research, 16(1), 11-19.

Grow, H. M., Saelens, B. E., Kerr, J., Durant, N. H., Norman, G. J., \& Sallis, J. F. (2008). Where are youth active? Roles of proximity, active transport, and built environment. Medicine \& Science in Sports \& Exercise, 40(12), 2071. Hennink, M., Hutter, I., \& Bailey, A. (2010). Qualitative research methods: Sage.

Holman, C., Donovan, R. J., \& Corti, B. (1996). Factors influencing the use of physical activity facilities: results from qualitative research. Health Promotion Journal of Australia: Official Journal of Australian Association of Health Promotion Professionals, 6(1), 16-21.
Humpel, N., Owen, N., \& Leslie, E. (2002). Environmental factors associated with adults' participation in physical activity - A review. American Journal of Preventive Medicine, 22(3), 188-199.doi:10.1016/s0749 -3797(01) 00426-3

Iran. Ministry of Islamic Culture. National Plans Office. (2010). Cultural Behavior of Iranian (SHIRAZ). Iran.Tehran.

Jansson, M., \& Persson, B. (2010). Playground planning and management: An evaluation of standard-influenced provision through user needs. Urban Forestry \& Urban Greening, 9(1), 33-42. doi: 10.1016/j.ufug.2009.10.003

Kaczynski, A. T., Besenyi, G. M., Stanis, S. A. W., Koohsari, M. J., Oestman, K. B., Bergstrom, R., Reis, R. S. (2014). Are park proximity and park features related to park use and park-based physical activity among adults? Variations by multiple socio-demographic characteristics. International Journal of Behavioral Nutrition and Physical Activity, 11(146), 0146-0144.

Kaczynski, A. T., Potwarka, L. R., \& Saelens, B. E. (2008). Association of park size, distance, and features with physical activity in neighborhood parks. American Journal of Public Health, 98(8), 1451-1456. doi: 10.2105/ajph.2007.129064

Larson, J. H., \& Lowe, W. (1990). Family cohesion and personal space in families with adolescents. Journal of family issues, 11(1), 101-108.

Lau, J. C., \& Chiu, C. C. (2003). Accessibility of low-income workers in Hong Kong. Cities, 20(3), 197-204.

Levinson, D. M. (1998). Accessibility and the journey to work. Journal of Transport Geography, 6(1), 11-21.

Lloyd, K., Burden, J., \& Kiewa, J. (2008). Young girls and urban parks: Planning for transition through adolescence. Journal of Park and Recreation Administration, 26(3).

Loukaitou-Sideris, A., \& Sideris, A. (2010). What Brings Children to the Park? Analysis and Measurement of the Variables Affecting Children's Use of Parks. Journal of the American Planning Association, 76(1), 89107, doi: 10.1080/01944360903418338

Lynch, K. (1977). Growing up in cities: Studies of the spatial environment of adolescence: Cambridge, MA: MIT Press.

McCormack, G. R., Rock, M., Toohey, A. M., \& Hignell, D. (2010). Characteristics of urban parks associated with park use and physical activity: A review of qualitative research. 
Health \& Place, 16(4), 712-726. doi: 10.1016/j.healthplace.2010.03.003

Mowen, A., Orsega-Smith, E., Payne, L., Ainsworth, B., \& Godbey, G. (2007). The role of park proximity and social support in shaping park visitation, physical activity, and perceived health among older adults. Journal of Physical Activity \& Health, 4(2), 167.

Mowen, A. J., \& Confer, J. J. (2003a). The relationship between perceptions, distance, and sociodemographic characteristics upon public use of an urban park "in-fill". Journal of Park and Recreation Administration, 21(3), 58-74.

Mowen, A. J., \& Confer, J. J. (2003b). The relationship between perceptions, distance, and socio-demographic characteristics upon public use of an urban park" in-fill". Journal of Park and Recreation Administration, 21(3), 58-74.

Mowen, A. J., Payne, L. L., \& Scott, D. (2005). Change and stability in park visitation constraints revisited. Leisure Sciences, 27(2), 191-204. doi: 10.1080/0149040059 0912088

Neuman, W. L. (2004). Basics of social research. Boston: Pearson.

Neuvonen, M., Slevanen, T., Tonnes, S., \& Koskela, T. (2007). Access to green areas and the frequency of visits - A case study in Helsinki. Urban Forestry \& Urban Greening, 6(4), 235-247. doi:10.1016/j.ufug. 2007.05.003

Oh, K., \& Jeong, S. (2007). Assessing the spatial distribution of urban parks using GIS. Landscape and urban planning, 82(1), 25-32.

Parra, D. C., Gomez, L. F., Fleischer, N. L., \& David Pinzon, J. (2010). Built environment characteristics and perceived active park use among older adults: Results from a multilevel study in Bogota. Health \& Place, 16(6), 1174-1181. doi:10.1016/j.healthplace. 2010.07.008

Pasaogullari, N., \& Doratli, N. (2004). Measuring accessibility and utilization of public spaces in Famagusta. Cities, 21(3), 225-232.

Payne, L., Orsega-Smith, E., Roy, M., \& Godbey, G. (2005). Local park use and personal health among older adults: an exploratory study. Journal of Park and Recreation Administration, 23(2), 1-20.

Potwarka, L. R., Kaczynski, A. T., \& Flack, A. L. (2008). Places to play: Association of park space and facilities with healthy weight status among children. Journal of Community Health, 33(5), 344-350.
Powell, K. E., Martin, L. M., \& Chowdhury, P. P. (2003). Places to walk: Convenience and regular physical activity. American Journal of Public Health, 93(9), 1519-1521. doi: 10.2105/ajph.93.9.1519

Raymore, L. A. (2002). Facilitators to leisure. Journal of Leisure Research, 34(1), 37-51.

Rey-López, J. P., Vicente-Rodríguez, G., Biosca, M., \& Moreno, L. A. (2008). Sedentary behaviour and obesity development in children and adolescents. Nutrition, Metabolism and Cardiovascular Diseases, 18(3), 242-251.

Ries, A. V., Voorhees, C. C., Roche, K. M., Gittelsohn, J., Yan, A. F., \& Astone, N. M. (2009). A Quantitative Examination of Park Characteristics Related to Park Use and Physical Activity Among Urban Youth. Journal of Adolescent Health, 45(3), S64S70. doi: 10.1016/j.jadohealth.2009.04.020

Sallis, J. F., Hovell, M. F., Hofstetter, C. R., Elder, J. P., Hackley, M., Caspersen, C. J., \& Powell, K. E. (1990). Distance between homes and exercise facilities related to frequency of exercise among San-Diego residents. Public Health Reports, 105(2), 179-185.

Saunders, M. N., Saunders, M., Lewis, P., \& Thornhill, A. (2009). Research Methods For Business Students (5 ed.): Pearson Education India

Schiavo, R. S. (1988). Age differences in assessment and use of a suburban neighborhood among children and adolescents. Children's Environments Quarterly, 5(2), 4-9.

Schipperijn, J., Ekholm, O., Stigsdotter, U. K., Toftager, M., Bentsen, P., KamperJorgensen, F., \& Randrup, T. B. (2010). Factors influencing the use of green space: Results from a Danish national representative survey. Landscape and urban planning, 95(3), 130-137. doi:10.1016/j.land urbplan.2009.12.010

Schipperijn, J., Stigsdotter, U. K., Randrup, T. B., \& Troelsen, J. (2010). Influences on the use of urban green space - A case study in Odense, Denmark. Urban Forestry \& Urban Greening, 9(1), 25-32. doi: 10.1016/j.ufug. 2009.09.002

Scott, D., \& Jackson, E. L. (1996). Factors that limit and strategies that might encourage people's use of public parks. Journal of Park and Recreation Administration, 14(1), 1-17.

Shiraz Municipality. (2010). The annual statistics of Shiraz City. Shiraz.

Shores, K. A., \& West, S. T. (2010). Rural and urban park visits and park-based physical activity. 
Preventive medicine, 50, S13-S17. doi: 10.1016/j.ypmed.2009.07.023

Tinsley, H. E. A., Tinsley, D. J., \& Croskeys, C. E. (2002). Park usage, social milieu, and psychosocial benefits of park use reported by older urban park users from four ethnic groups. Leisure Sciences, 24(2), 199-218. doi: 10.1080/01490400252900158

Travlou, P., \& Ward Thompson, C. (2007). Mapping youth spaces in the public realm: identity, space and social exclusion. Open space: people space, 71-82.

Troped, P. J., Saunders, R. P., Pate, R. R., Reininger, B., Ureda, J. R., \& Thompson, S. J. (2001). Associations between self-reported and objective physical environmental factors and use of a community rail-trail. Preventive medicine, 32(2), 191-200. doi: 10.1006/pm ed.2000.0788

Tucker, P., Gilliland, J., \& Irwin, J. I. (2007). Splashpads swings, and shade - Parents' preferences for neighbourhood parks. Canadian Journal of Public Health-Revue Canadienne De Sante Publique, 98(3), 198202.

Van Herzele, A., \& Wiedemann, T. (2003). A monitoring tool for the provision of accessible and attractive urban green spaces. Landscape and urban planning, 63(2), 109126. doi: 10.1016/s0169-2046(02)00192-5
Veitch, J., Bagley, S., Ball, K., \& Salmon, J. (2006). Where do children usually play? A qualitative study of parents' perceptions of influences on children's active free-play. Health \& Place, 12(4), 383-393. doi:10.1016/j.healthplace.2005.02.009

Veitch, J., Salmon, J., \& Ball, K. (2007). Children's perceptions of the use of public open spaces for active free-play. Children's Geographies, 5(4), 409-422.

Veitch, J., Salmon, J., \& Ball, K. (2008). Children's active free play in local neighborhoods: a behavioral mapping study. Health education research, 23(5), 870-879.

Walker, J. R., \& Crompton, J. L. (2012). The relationship of household proximity to park use. Journal of Park and Recreation Administration, 30(3), 52-63.

Wang, D., Brown, G., \& Liu, Y. (2015). The physical and non-physical factors that influence perceived access to urban parks. Landscape and urban planning, 133, 53-66.

Wang, D., Brown, G., \& Mateo-Babiano, D. (2013). Beyond proximity: an integrated model of accessibility for public parks. Asian Journal of Social Sciences \& Humanities, 2(3), 486498.

Wang, D., Mateo-Babiano, I., \& Brown, G. (2013). Rethinking Accessibility in Planning of Urban Open Space Using an Integrative Theoretical Framework. Paper presented at the SOAC 2013: 6th State of Australian Cities Conference. 